\title{
Permeability Characteristics of Tailings considering Chemical and Physical Clogging in Lixi Tailings Dam, China
}

\author{
Zengguang Xu, ${ }^{1}$ Xuemin Yang, Junrui Chai, ${ }^{1,2}$ Yuan Qin, ${ }^{1}$ and Yanlong Li ${ }^{1}$ \\ ${ }^{1}$ State Key Laboratory Base of Eco-Hydraulic Engineering in Arid Area, Xi'an University of Technology, Xian, Shaanxi 710048, China \\ ${ }^{2}$ College of Hydraulic and Environmental Engineering, China Three Gorges University, Yichang, Hubei 443002, China \\ Correspondence should be addressed to Zengguang Xu; xuzengguang@xaut.edu.cn
}

Received 22 January 2016; Accepted 21 March 2016

Academic Editor: Jun Wu

Copyright (c) 2016 Zengguang Xu et al. This is an open access article distributed under the Creative Commons Attribution License, which permits unrestricted use, distribution, and reproduction in any medium, provided the original work is properly cited.

\begin{abstract}
Chemical and physical clogging frequently occur in tailings dam. The clogging seriously influences the safety of tailings dam. This paper conducts several column experiments to analyse the physical and chemical clogging of the Lixi tailings dam in China. The experiment results of chemical clogging show that average flow velocity and permeability decrease by approximately $50 \%$ to $60 \%$. The experiment results of physical clogging show that these values decrease by approximately $50 \%$ to $70 \%$. For physical clogging, a higher hydraulic gradient could result in a larger extent of decrease in the permeability coefficient. The permeability did not decrease when the hydraulic gradient was equal to 0.125 . The results of chemical clogging column experiments show that ferrous ion solution concentration is disproportional to the permeability coefficient. This scenario can be attributed to the extremely small concentration gradients.
\end{abstract}

\section{Introduction}

Clogging is a ubiquitous phenomenon in nature and in such projects as tailings dams, nuclear waste disposal, and wastewater treatment [1-4]. These processes usually produce precipitation and cause a reduction of porosity and permeability [1]. Owing to nonhomogeneous particle and existence of different ions, clogging frequently occurs in tailings dams. This scenario seriously influences the safety of a tailings dam. For example, the Fonte Santa mine tailings dam in Northeast Portugal failed on November 27, 2006, on account of extraordinary rainfall and eventual clogging of the spillway [5]. Thus, clogging is becoming a major public concern.

Clogging can be classified as chemical, physical, or biological clogging. Knowles et al. [6] identified different physical, chemical, and biological factors responsible for clogging. The results showed that clogging was a major operational and maintenance issue associated with the use of subsurface flow wetlands for wastewater treatment and can ultimately limit the system lifetime. Several types of clogging can occur in a system. Two or three types of clogging can occur simultaneously or in any order. Li et al. [7] analysed the hydraulic conductivity of kaolin under different chemical and biochemical conditions. Song et al. [8] investigated the chemical and physical effects of sump screen clogging in containment materials. Wang et al. [9] revealed the microbial community structure of clogging in dewatering wells in an open-cast mining area. Poonoosamy et al. [10] analysed the dissolution-precipitation processes that could cause porosity changes by tank experiments. The particle size of a tailings dam is nonhomogeneous, and its leachate contains different ions. Thus, under certain conditions, physical and chemical clogging may both simultaneously occur in a tailings dam. However, few researchers have studied simultaneous physical and chemical clogging. Thus, an in-depth study on simultaneous chemical and physical clogging is necessary.

Similarities and differences exist between physical and chemical clogging. The two types of clogging decrease the permeability coefficient at the macrolevel. However, their mechanisms are different at the microlevel. The cause of physical clogging is the particles' inhomogeneity. Small particles move into and block the pore sundering seepage action, which lead to the decrease in permeability coefficient. Clogging then occurs. The cause of chemical clogging is chemical 
precipitation $[1,8]$. The leachate of a tailings dam usually contains heavy metal ions, such as ferrous ions, copper ions, and aluminium ions. These ions can experience redox reactions and produce precipitation. Redox reaction occurs and generates precipitation that can block pores whenever oxygen is sufficient. Chemical clogging then occurs.

Experiments are effective approaches to investigate clogging. Many laboratory column experiments have been conducted to observe the decrease in hydraulic conductivity in chemical, biological, and physical clogging. For example, columns filled with porous media were percolated by water, which usually contains the nutrients necessary for microorganism growth. Changes in the hydraulic conductivity can be measured by monitoring the flow rate and the hydraulic head differences along the column [11-15]. Laboratory columns were also used to study chemical clogging similar to bioclogging and physical column experiments [16-21]. Models that incorporate relevant permeability and clogging are also built to design such systems [22-25].

Meanwhile, studies of tailings dams considering physical and chemical clogging are very few. Some of the studies diverge from reality. For example, the concentration of the ion solutions or the water head is too high. And there are few studies that have researched the influence of hydraulic gradient on physical clogging.

This paper focuses on the physical and chemical clogging of Lixi tailings dam by performing experiments. Firstly, water samples obtained from the Lixi tailings dam (Shaanxi, China) were analysed with a DR 2800 spectrophotometer to measure the water sample concentrations as close to the actual situation as possible. Experiments were then conducted on a laboratory-scale column on the basis of water sample concentration data to study the relationship between hydraulic conductivity and time.

Tailings samples were also obtained from the Lixi tailings dam. The tailings particle size was analysed. Physical clogging experiments on a laboratory-scale column modelled on the tailings particle size obtained from the Lixi tailings dam were also conducted to research the relationship between hydraulic conductivity and time. The experimental conditions were sufficiently controlled to provide a reliable database. Finally, we compared the chemical and physical clogging conditions.

\section{Project Profile and Set Investigation}

The Lixi tailings dam is a valley-type tailings dam and is located in Hua county of Shanxi province, China. It was built in 1978 and started operating in 1983. Its location could be seen in Figure 1. The purpose of the Lixi tailings dam is to stock slag. The slag mainly consists of medium tailings. The Lixi tailings dam is formed by two period dams. The initial dam that is used to support the slag was built with gravel at a height of 40.5 meters. This initial dam has strong water permeability. The latter dam was formed by slag. The slag was accumulated by instalment through the upstream method. More than 30 retaining dams were formed by slag. Figure 2 shows a picture of the current situation of the Lixi tailings dam on December 10, 2012. The average downstream slope

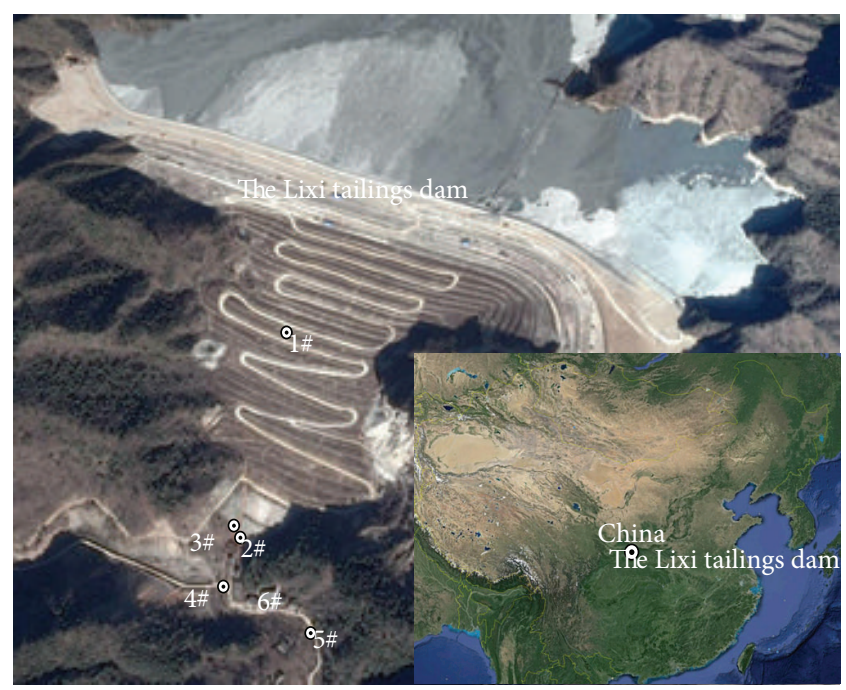

FIgURE 1: The location of Lixi tailings dam.

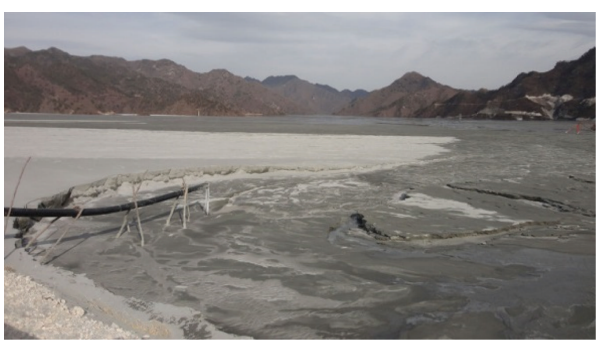

Figure 2: Current situation of the Lixi tailings dam (December 10, 2012).

of the retaining dams is $1: 5$. The Lixi tailings dam's height was designed to be 164.5 meters, its designed capacity is 165 million cubic meters, and its service length is 32 years. This dam is a second-class tailings dam.

Firstly, to ensure a full understanding of the ion concentration in the tailings leachate of the Lixi tailings dam, six different sites (see Figure 1) were selected and three types of ions (i.e., ferrous ion, total iron, and hexavalent chromium) were tested using a DR 2800 spectrophotometer. The six sites were selected along different dam heights. The test results are listed in Table 1.

The data in Table 1 showed that the ferrous ion concentration was high. Ferrous ion can produce redox reactions and precipitation such as iron hydroxide. Finally, the precipitations clog the tailings and drain porosity that decreases permeability. Figure 3 shows chemical clogging in the Lixi tailings dam.

Secondly, we brought tailings samples from the Lixi tailings dam to the laboratory to analyse the tailings composition in the dam. This sample was dried and sieved to determine its sizes (Table 2).

\section{Experimental Methods}

3.1. Physical Clogging Experimental Method. Figure 4 shows picture of the physical clogging experimental setup. The 
TABLE 1: Three ion concentrations of the Lixi tailings dam at different sites (mg/L).

\begin{tabular}{lcccccc}
\hline Number & $1 \#$ & $2 \#$ & $3 \#$ & $4 \#$ & $5 \#$ & 6\# \\
\hline Location & $\begin{array}{c}\text { The middle of } \\
\text { tailings dam }\end{array}$ & $\begin{array}{c}\text { Left bank of } \\
\text { the initial dam }\end{array}$ & $\begin{array}{c}\text { Right bank of } \\
\text { the initial dam }\end{array}$ & $\begin{array}{c}\text { River's } \\
\text { upstream }\end{array}$ & $\begin{array}{c}\text { River's } \\
\text { downstream }\end{array}$ & $\begin{array}{c}\text { The middle of } \\
\text { the river }\end{array}$ \\
Ferrous ion & 0.49 & 0.13 & 0.16 & 0.28 & 0.24 & 0.37 \\
Total iron & 1.36 & 5.32 & 4.02 & 1.09 & 1.02 & 1.04 \\
Hexavalent chromium & 0.001 & 0.047 & 0.044 & 0.011 & 0.012 & 0.015 \\
\hline
\end{tabular}

TABLE 2: Tailings sizes obtained from the Lixi tailings dam.

\begin{tabular}{lc}
\hline Nominal diameter $(\mathrm{mm})$ & Percentage composition $(\%)$ \\
\hline 0.63 & 6.04 \\
0.315 & 38.32 \\
0.16 & 37.68 \\
0.08 & 9.32 \\
$<0.08$ & 8.14 \\
\hline
\end{tabular}

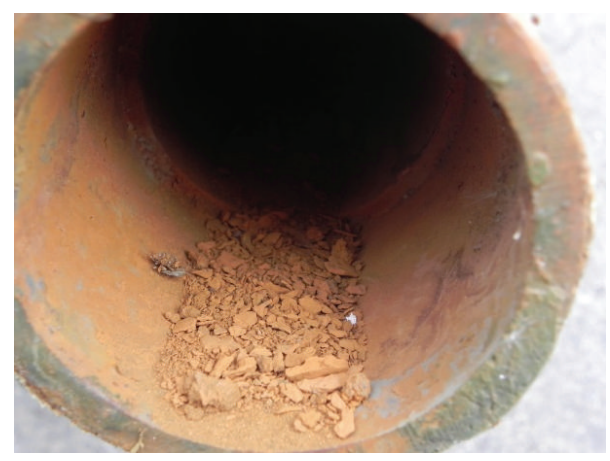

(a)

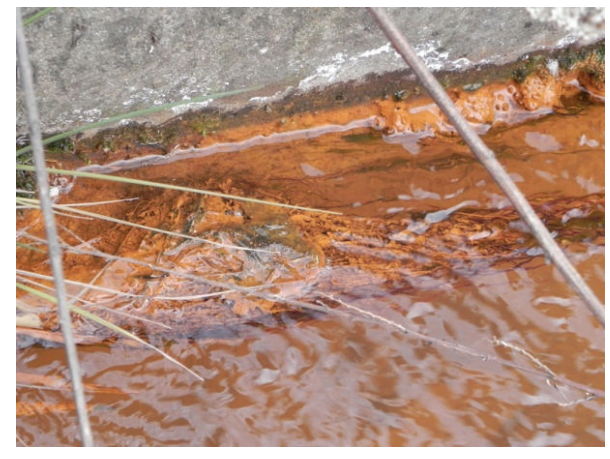

(b)

FIGURE 3: The chemical clogging of the Lixi tailings dam ((a) drainpipe, (b) surface drain).

diameter of the entire column was $5 \mathrm{~cm}$ and its height was $14 \mathrm{~cm}$. The first $2 \mathrm{~cm}$ from the inlet was a water column that flowed from the water tank. A steel mesh separated the water column and transition layer. Approximately $2 \mathrm{~cm}$ of transition layer filled the top of the water column. An $8 \mathrm{~cm}$ tailings column was also placed at the transition layer top. Above the $8 \mathrm{~cm}$ tailings column, there also was a $2 \mathrm{~cm}$ water column linking the outlet. The water tank was used to maintain a steady water level during the experiments.

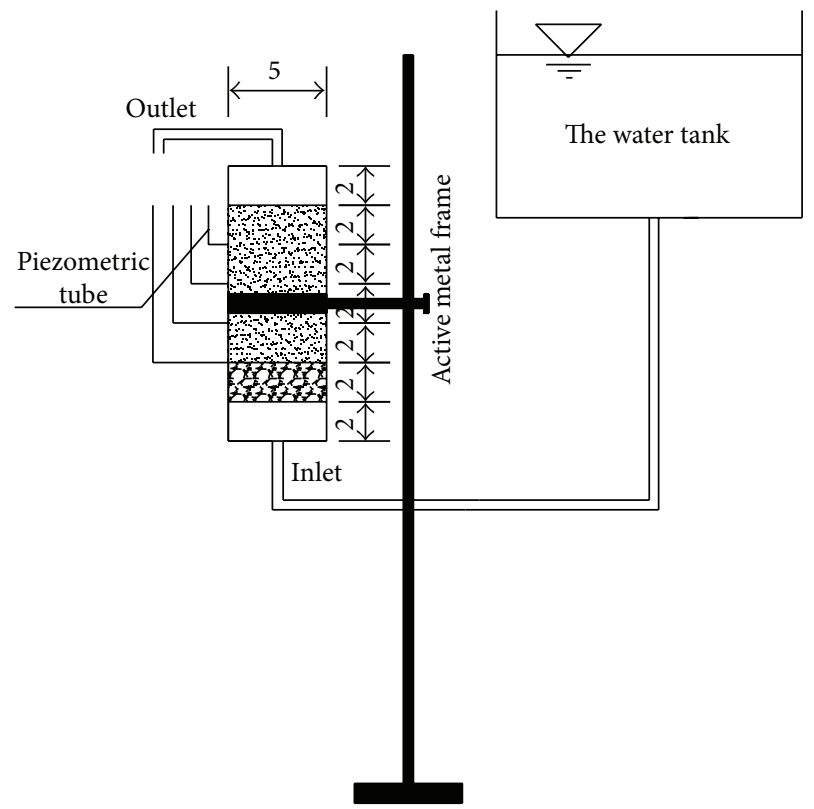

FIGURe 4: Physical clogging experimental setup (all distance numbers in the figure are in $\mathrm{cm}$ ).

The height difference of the water tank and column formed different hydraulic gradients.

Table 2 indicates that the sizes of $0.315 \mathrm{~mm}$ and $0.16 \mathrm{~mm}$ account for $76 \%$ of the total tailings. The proportion of the two sizes is near $1: 1$. Thus, the two tailings sizes were used for physical clogging experiments. So the $8 \mathrm{~cm}$ long clean tailings column was filled with a mixture of $0.315 \mathrm{~mm}$ and $0.16 \mathrm{~mm}$ tailings cleaned with water at $1: 1$ proportion. The column experiment characteristics are shown in Table 3 . The tailings column packing was as homogeneous as possible. The hydraulic gradient had a fixed value from the beginning of the experiments to the end. The flow direction was upwards from the inlet chamber to outlet chamber at the top. This approach ensured that all of the tailings were saturated. Four piezometric tubes (i.e., p1, p2, p3, and p4) were placed in the column. $\mathrm{p} 1$ was located between the tailings and transition layer. The remaining three piezometric tubes were $2 \mathrm{~cm}$ higher than one another, as shown in Figure 4. The four piezometric tubes were used to observe the change in permeability coefficient at different heights. During the experiment, the air was exhausted through the four piezometric tubes.

Four groups of physical clogging experiments (i.e., experiments $1,2,3$, and 4 ) were designed. The only difference 
TABLE 3: Characteristics of the physical column experiments.

\begin{tabular}{lc}
\hline Parameter & Value \\
\hline Column diameter & $5 \mathrm{~cm}$ \\
Column length & $14 \mathrm{~cm}$ \\
$\begin{array}{l}\text { Distance between inlet and } \\
\text { transition layer }\end{array}$ & $2 \mathrm{~cm}$ \\
Tailings column length & $8 \mathrm{~cm}$ \\
Tailings size & $0.315 \mathrm{~mm}$ and $0.16 \mathrm{~mm}$ \\
Tailings proportion & $1: 1$ \\
Tailings weight & $0.237 \mathrm{~kg}$ \\
Hydraulic gradient (experiments 4, & $1.25,0.625,0.25$, and 0.125 \\
5,6, and 7) &
\end{tabular}

between the four groups of experiments was the hydraulic gradient. Experiment 1 had a hydraulic gradient of 1.25 . Experiments 2, 3, and 4 had hydraulic gradients of 0.625 , 0.25 , and 0.125 , respectively. Each of the hydraulic gradients remained unchanged. All other experimental conditions were the same in the four groups of physical clogging experiments. The hydraulic gradient was measured by the four piezometric tubes at different heights. The tailings columns were continuously fed with clean water during the experiments. The changes in hydraulic conductivity with time were monitored by measuring the water head changes between two piezometric tubes and flow across the tailings column.

3.2. Chemical Clogging Experimental Method. The ferrous ion's concentration was the highest based on the set investigation results of the tailings leachate in Table 1. Thus, ferrous ion was used to analyse chemical clogging in this study. Ferrous ion oxidises when it comes into contact with air. This reaction then produces iron oxide that is nonsoluble and blocks the pore. Several column experiments were designed to determine how ferrous ion causes chemical clogging.

The chemical clogging column experiments and their setups were similar to those of physical clogging. Figure 5 shows picture of the chemical clogging experimental setup. The diameter of the entire column was $5 \mathrm{~cm}$ and its height was $14 \mathrm{~cm}$. The first $2 \mathrm{~cm}$ from the inlet was a water column that flowed from the water tank. A steel mesh separated the water column and tailings. Approximately $10 \mathrm{~cm}$ of tailings filled the top of the water column. A $2 \mathrm{~cm}$ water column was also placed at the column top linking the outlet. There was no transition layer in the physical clogging to avoid the clogging in it. The water tank was used to maintain a steady water level during the experiments. The ferrous solution was in the water tank.

The tailings columns were continuously fed with a solution. The changes in hydraulic conductivity with time were monitored by measuring the flow across the tailings column. The four piezometric tubes along the tailings column were not used in the chemical clogging experiments because the experimental results show that clogging only occurred in the $1 \mathrm{~cm}$ to $2 \mathrm{~cm}$ section above the tailings bottom (during the experiment, the air was exhausted through the four

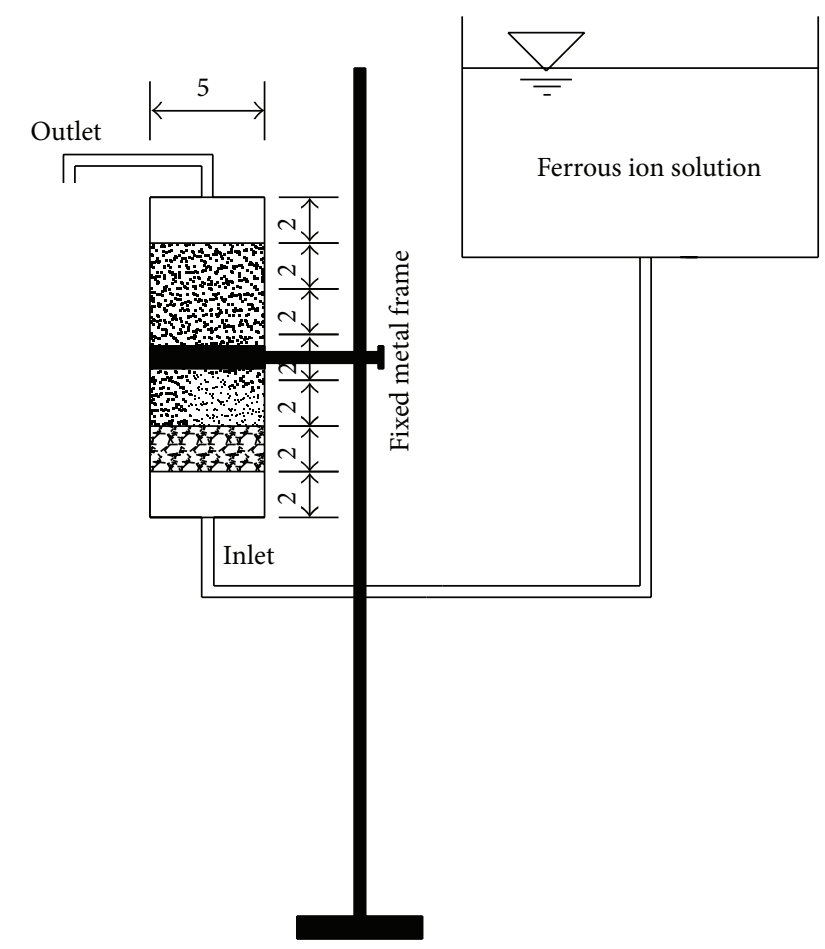

FIGURE 5: Chemical clogging experimental setup (distance numbers are all in $\mathrm{cm}$ ).

piezometric tubes). Thus, we focused on the entire tailings column's permeability coefficient in chemical clogging.

Three ferrous solution concentrations were prepared to observe how the different concentrations influence chemical clogging. The three concentrations were all produced on the basis of the data in Table 1 to approximate the actual situation. These concentrations were $0.4 \mathrm{mg} / \mathrm{L}$ to $0.5 \mathrm{mg} / \mathrm{L}, 0.3 \mathrm{mg} / \mathrm{L}$ to $0.4 \mathrm{mg} / \mathrm{L}$, and $0.2 \mathrm{mg} / \mathrm{L}$ to $0.3 \mathrm{mg} / \mathrm{L}$. So there were 3 groups of column experiments designed in the chemical clogging (i.e., experiments 5,6 , and 7 ). The solution was configured with a DR 2800 spectrophotometer.

All the tailings columns were filled with homogeneous tailings in the chemical clogging column experiments. The data in Table 2 showed that the tailings size of $0.315 \mathrm{~mm}$ was selected because its proportion is the largest among the components of the Lixi tailings dam. Three experiment groups were organized in chemical clogging. Each experiment used a fixed hydraulic gradient of 0.5 . The only difference was the ferrous ion solution concentration. The characteristics of chemical clogging column experiments are listed in Table 4.

\section{Experimental Results}

4.1. Physical Clogging Column Experimental Results. The results of the physical clogging experiments showed that the average velocity in the tailings column decreased firstly and then remained substantially constant, which is similar to the chemical clogging results. The data in Figures 6 and 8 showed that the average flow velocity had a rapid decrease in the first 15 hours. Figure 10 showed that this decrease occurred in 30 
TABLE 4: Characteristics of the chemical column experiments.

\begin{tabular}{lc}
\hline Parameter & Value \\
\hline Column diameter $(\mathrm{cm})$ & 5 \\
Column length $(\mathrm{cm})$ & 14 \\
Distance between inlet and tailings $(\mathrm{cm})$ & 2 \\
Tailings column length $(\mathrm{cm})$ & 10 \\
Tailings size $(\mathrm{mm})$ & 0.315 \\
Tailings weight $(\mathrm{kg})$ & 0.245 \\
Hydraulic gradient & 0.5 \\
Ferrous ion solution concentrations $(\mathrm{mg} / \mathrm{L})$ & $0.4-0.5,0.3-0.4$, and \\
\end{tabular}

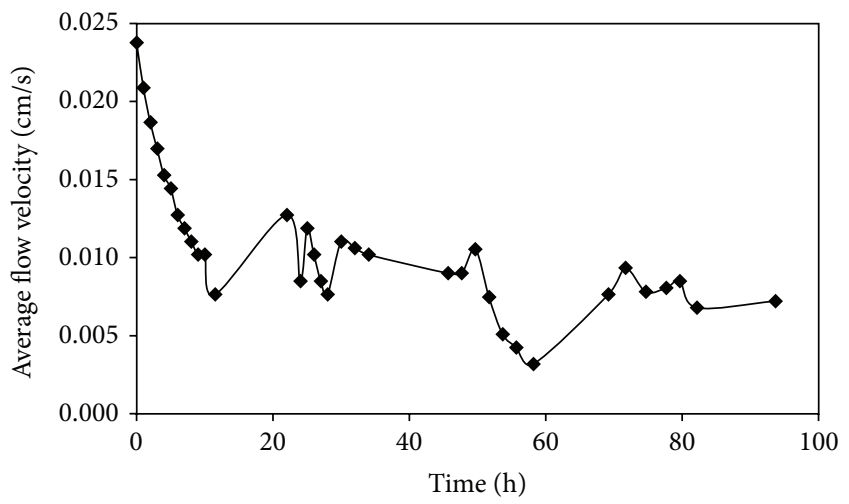

FIGURE 6: Relationship between the average flow velocity in the tailings column and time under the hydraulic gradient of 1.25 (experiment 1 ).

hours. All the average flow velocity values remained stable after the decreasing stage. These values decreased by $69.6 \%$, $66.5 \%$, and $55.6 \%$ under the hydraulic gradients of $1.25,0.625$, and 0.25 , respectively. In Figure 12, the average flow velocity slowly decreases by $38.4 \%$.

The tailings column in physical clogging was artificially divided into three small columns along the height. The lowest layer was between $\mathrm{p} 1$ and $\mathrm{p} 2$, the middle layer was between $\mathrm{p} 2$ and $\mathrm{p} 3$, and the top layer was between $\mathrm{p} 3$ and $\mathrm{p} 4$. The distance between every two piezometric tubes was $2 \mathrm{~cm}$.

The permeability coefficients $K 1, K 2$, and $K 3$ (all expressed in $k t$ ) for the tailings column between the two piezometric tubes were calculated from the observed changes in average hydraulic head gradients. Figures $7,9,11$, and 13 are the relationship curves between $k t / k 0$ and time of the tailings column at different heights under the different hydraulic gradients. These hydraulic gradients were 1.25, $0.625,0.25$, and 0.125 , respectively. Figure 14 shows the change permeability coefficient over time under different hydraulic gradients.

Figures 7, 9, and 11 showed that all the lowest layers' permeability coefficient decreased, which confirms that physical clogging occurred in this layer. Figure 13 showed that this phenomenon did not occur at the hydraulic gradient of 0.125 . This observation suggests that a critical water head exists to avoid physical clogging. Figures 9, 11, and 13 showed

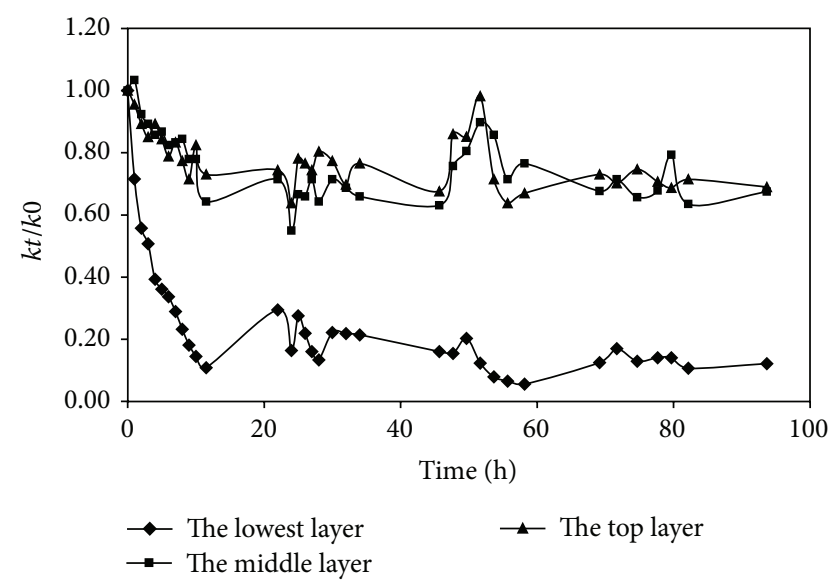

FIgURE 7: Relationship between $k t / k 0$ and time in different layers under the hydraulic gradient of 1.25 (experiment 1 ).

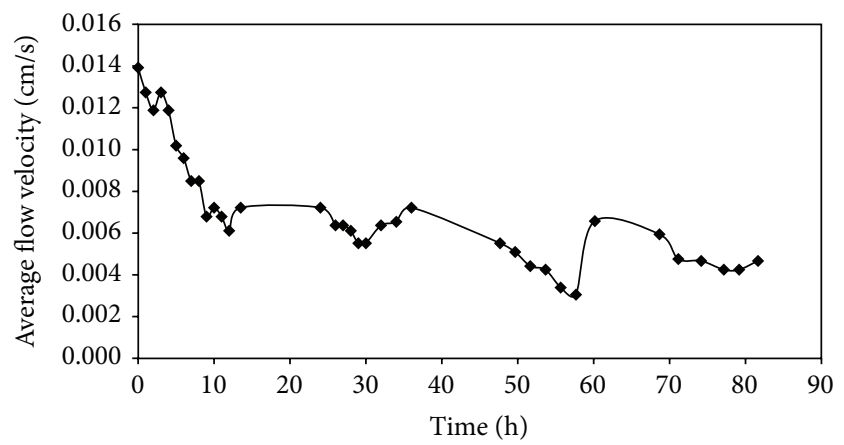

FIGURE 8: Relationship between the average flow velocity in the tailings column and time under the hydraulic gradient of 0.625 (experiment 2).

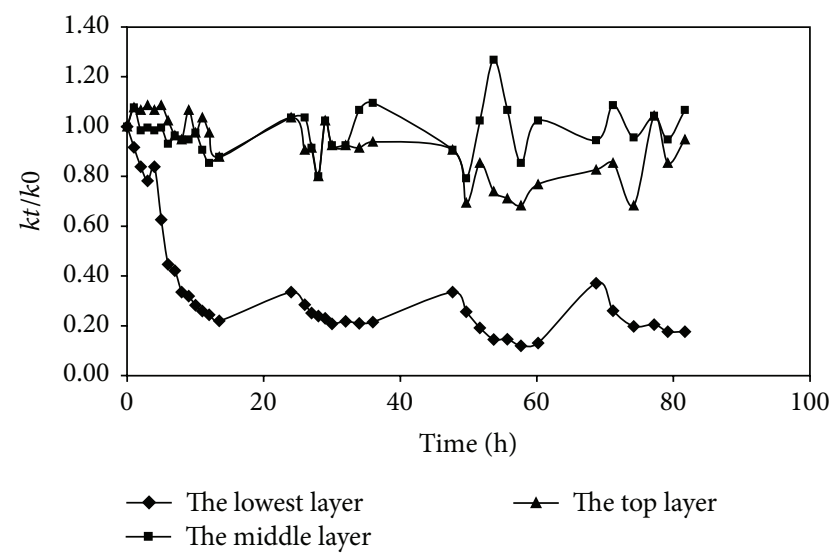

FIGURE 9: Relationship between $k t / k 0$ and time in different layers under the hydraulic gradient of 0.625 (experiment 2).

that the permeability coefficient in the middle and top layers remained approximately the same. However, Figure 7 showed that the permeability coefficient in the two layers decreased at the hydraulic gradient of 1.25 . This observation showed that physical clogging can deepen with a higher water head. Thus, the water head largely influenced the physical clogging. 


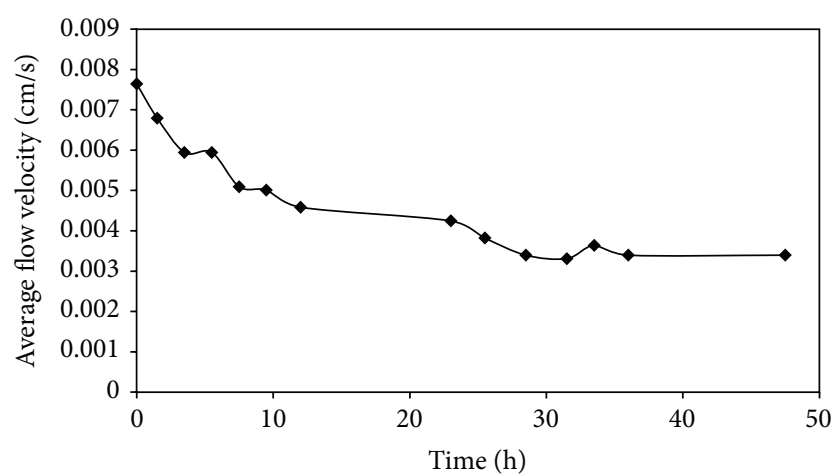

FIGURE 10: Relationship between the average flow velocity in the tailings column and time under the hydraulic gradient of 0.25 (experiment 3).

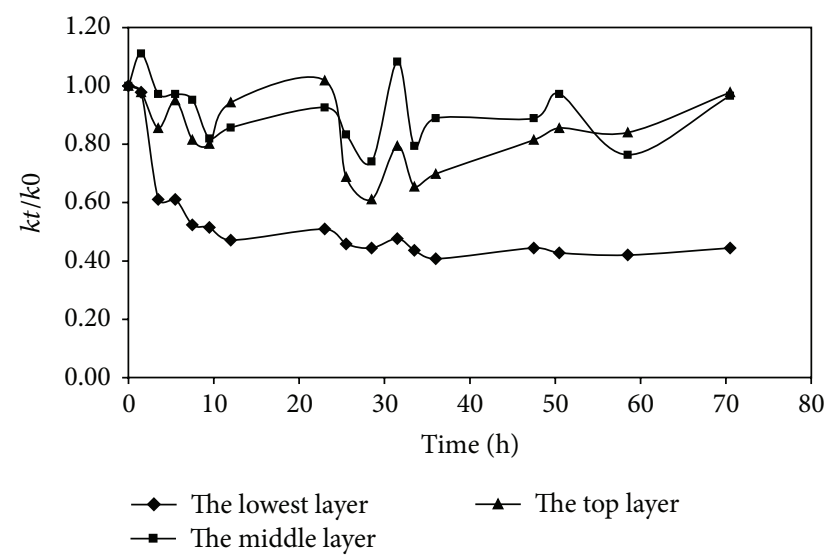

FIGURE 11: Relationship between $k t / k 0$ and time in different layers under the hydraulic gradient of 0.25 (experiment 3 ).

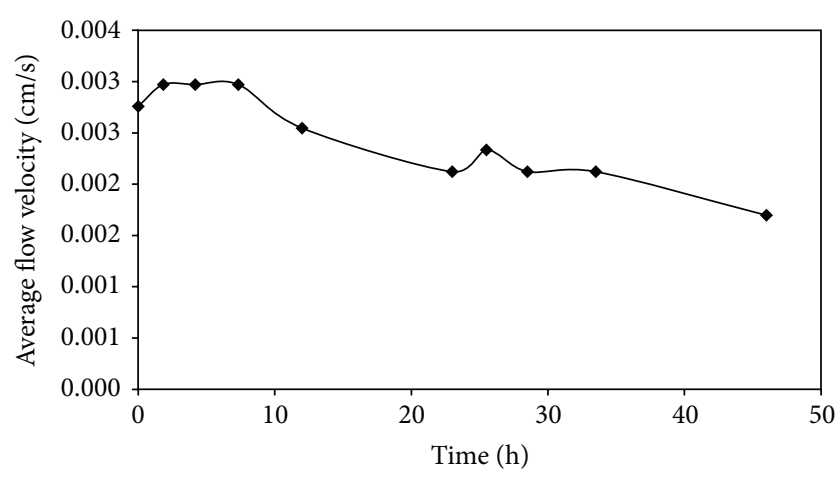

Figure 12: Relationship between the average flow velocity in the tailings column and time under the hydraulic gradient of 0.125 (experiment 4).

Does a higher hydraulic gradient increase the clogging speed? Figure 14 showed that the permeability coefficient always reached a fixed value. However, the time to reach the fixed value was essentially the same. Thus, the experiments did not prove that a higher hydraulic gradient resulted in faster clogging speed. Figure 14 showed that the permeability coefficients that reached the fixed value were different. This

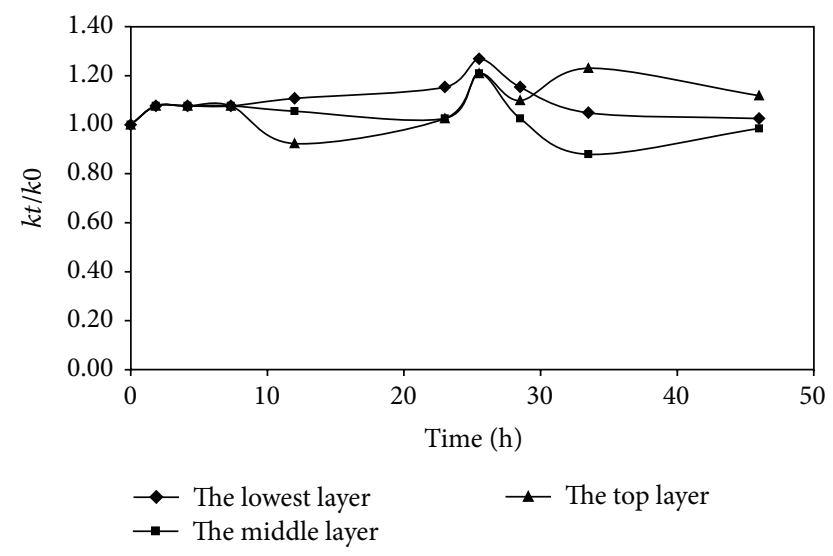

FIGURE 13: Relationship between $k t / k 0$ and time in different layers under the hydraulic gradient of 0.125 (experiment 4).

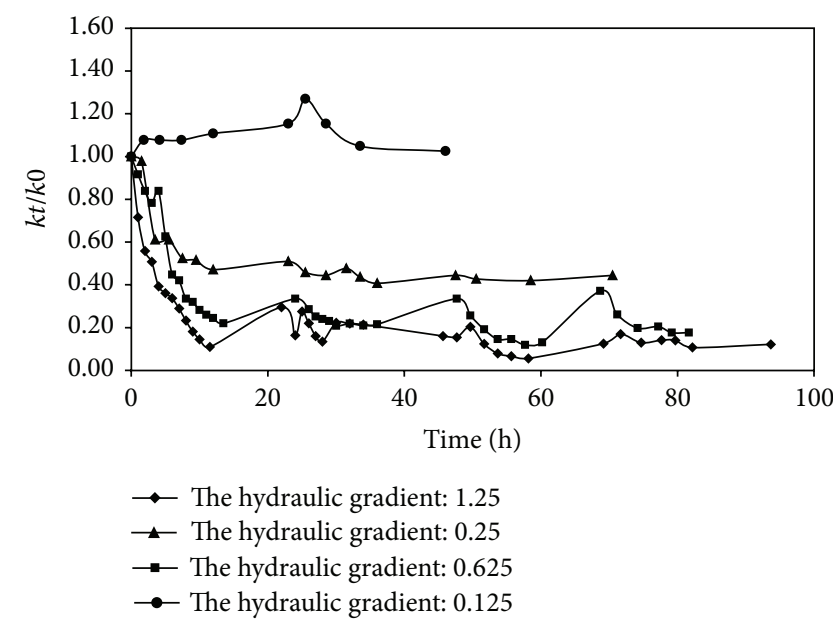

FIGURE 14: Relationship between $k t / k 0$ and time in the lowest layers under different hydraulic gradients.

condition implies that the higher the hydraulic gradient, the smaller the permeability.

4.2. Chemical Clogging Column Experimental Results. Three groups of column experiments were organized for chemical clogging. The experiment results showed that the average velocity in the tailings column decreased. The average flow velocity continued to decline in the first 100 hours and then remained stable in Figure 15. The drop in the average flow velocity reached $56.6 \%$ in experiment 5 . Experiments 6 and 7 reached $94.4 \%$ and $55.8 \%$, respectively.

The permeability coefficient, $k t$, for the $10 \mathrm{~cm}$ tailings column was calculated in the fixed hydraulic gradient: 0.5 . The initial permeability coefficients $k 0$ of the three experiments were, respectively, $4.9 \times 10^{-4} \mathrm{~m} / \mathrm{s}, 4.2 \times 10^{-4} \mathrm{~m} / \mathrm{s}$, and 4.0 $\times 10^{-4} \mathrm{~m} / \mathrm{s}$. Figure 16 is the three relation curves between $k t / k 0$ and time under different concentrations of ferrous ion solution. The permeability falling rate of experiment 6 is the fastest, while the falling rate of the concentration of 0.4$0.5 \mathrm{mg} / \mathrm{L}$ is in the second place. The falling rate of experiment 7 


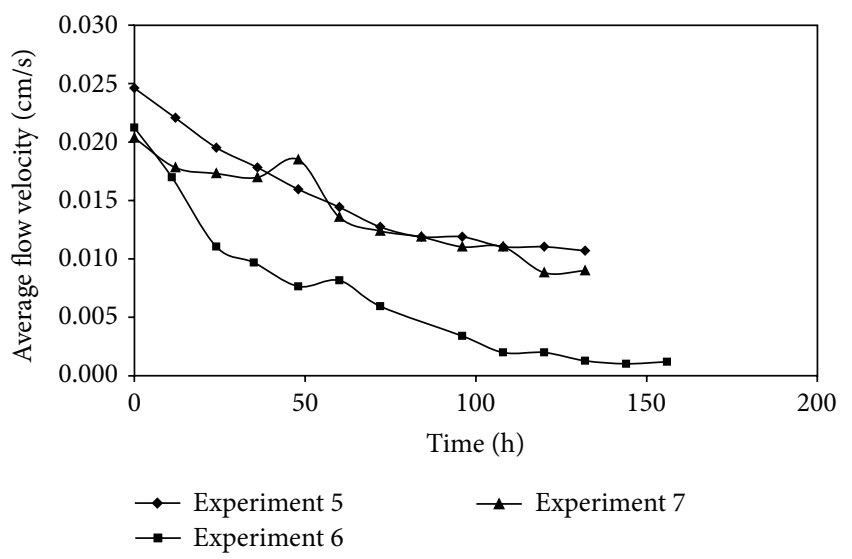

FIGURE 15: Relationship between the average flow velocity in the tailings column and time.

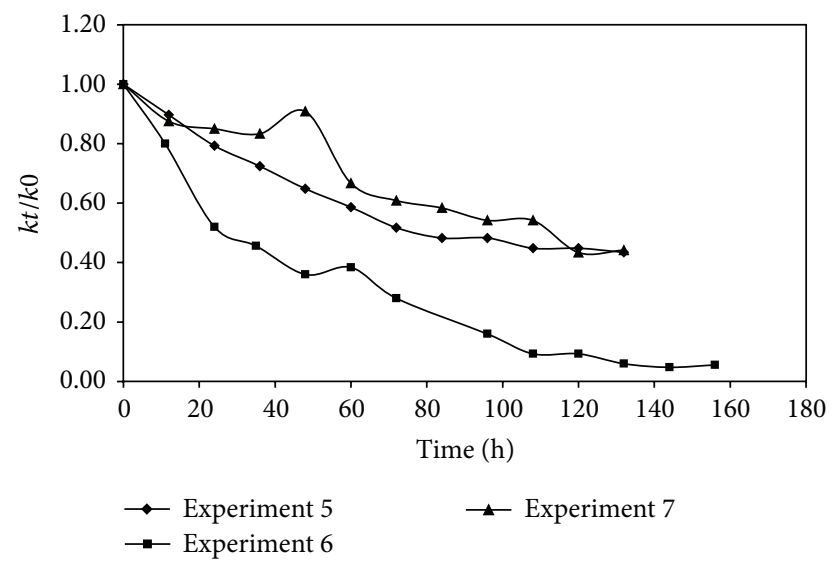

FIGURE 16: Relationship between $k t / k 0$ and time of the entire tailings column.

is the lowest. The phenomenon of the drop of the average flow velocity and permeability coefficient shows that the concentration of the ferrous ion solution is not proportional to the permeability coefficient. The reason may be that the gradients of the concentration were too small. But in the three experiments the permeability coefficients all had a drop.

\section{Comparison of Physical and Chemical Clogging}

To research how clogging in the Lixi tailings dam occurs, another clogging column experiment was done. The condition and procedure of experiment were similar to the above chemical clogging experiments. The tailings obtained from the Lixi tailings dam were used to fill the column in this experiment. The ferrous ion solution concentration was from $0.4 \mathrm{mg} / \mathrm{L}$ to $0.5 \mathrm{mg} / \mathrm{L}$. Physical and chemical clogging both occur in this experiment because of the tailings heterogeneity obtained from the Lixi tailings dam. Figure 17 shows the relationship between $k t / k 0$ and time. Two curves are shown in this chart. The top curve is the chemical clogging experiment 5 in the ferrous ion solution of $0.4 \mathrm{mg} / \mathrm{L}$ to

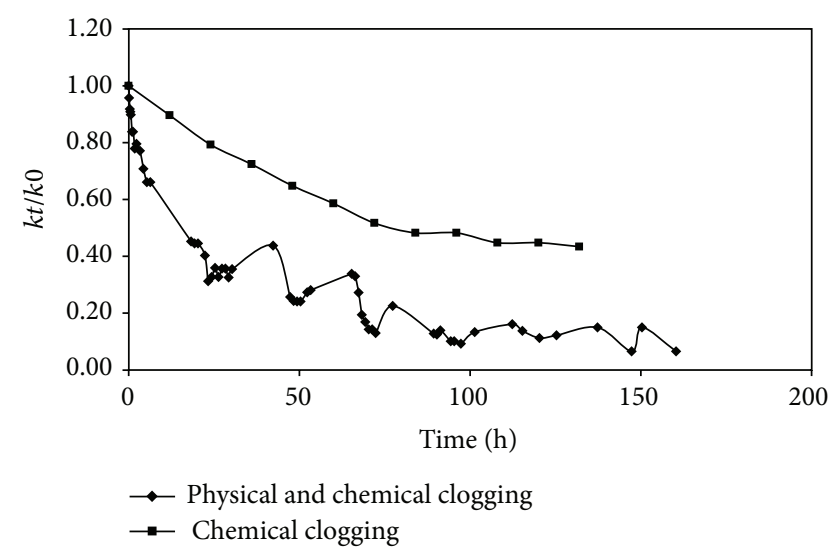

FIGURE 17: Relationship between $k t / k 0$ and time in the lowest layers in physical and chemical clogging.

$0.5 \mathrm{mg} / \mathrm{L}$ introduced in Section 4.2. The bottom curve is the physical and chemical clogging experiment. Under the same experimental condition, the difference between two curves showed the contribution of physical clogging. The results showed that the physical and chemical clogging were important for permeability of tailings.

\section{Conclusion}

All the experiments reveal the reduction in tailings permeability. This result proves the existence of clogging in the Lixi tailings dam. The average flow velocity and permeability coefficient in the chemical clogging experiments decreased by approximately $50 \%$ to $60 \%$. These factors decreased by approximately $50 \%$ to $70 \%$ in the physical clogging experiments. The time to reach a clogging balance in the chemical clogging experiments was approximately 100 hours, whereas the physical clogging experiments required only an extra 10 hours. Thus, physical and chemical clogging can both occur in the Lixi tailings dam. When physical clogging reached a balance, chemical clogging continued to decrease the permeability. Finally, the permeability can decrease by less than $50 \%$. This condition can seriously influence dam safety.

\section{Competing Interests}

The authors declare that they have no competing interests.

\section{Acknowledgments}

This work was supported by the National Natural Science Foundation of China (51409206, 51409208), Program 2013KCT-15 for Shaanxi Provincial Key Innovative Research Team, the Science Research Plan Project of Xi'an University of Technology (2015CX015), and the Innovative Research Team of Institute of Water Resources and Hydro-Electric Engineering, Xian University of Technology. 


\section{References}

[1] J. Wu, Mechanism and process simulation for chemical clogging of the tailings dam [Ph.D. thesis], Shanghai Jiao Tong University, 2008.

[2] T. Ishibashi, S. Tsuchino, S. Matsumoto, and F. Kasahara, "Clogging of HEPA filters by soot during fire events in nuclear fuel cycle facilities," Nuclear Technology, vol. 187, no. 1, pp. 57-68, 2014.

[3] H. S. Kandra, D. McCarthy, T. D. Fletcher, and A. Deletic, "Assessment of clogging phenomena in granular filter media used for stormwater treatment," Journal of Hydrology, vol. 512, pp. 518-527, 2014.

[4] R. Al-Isawi, M. Scholz, Y. Wang, and A. Sani, "Clogging of vertical-flow constructed wetlands treating urban wastewater contaminated with a diesel spill," Environmental Science and Pollution Research, vol. 22, no. 17, pp. 12779-12803, 2014.

[5] M. J. Franca, L. Gezero, and R. M. L. Ferreira, "The failure of the Fonte Santa mine tailing dam (Northeast Portugal)," in Proceedings and Monographs in Engineering Water and Earth Sciences, pp. 1153-1160, 2008.

[6] P. Knowles, G. Dotro, J. Nivala, and J. García, "Clogging in subsurface-flow treatment wetlands: occurrence and contributing factors," Ecological Engineering, vol. 37, no. 2, pp. 99-112, 2011.

[7] Z. Z. Li, T. Katsumi, T. Inui, and A. Takai, "Fabric effect on hydraulic conductivity of kaolin under different chemical and biochemical conditions," Soils and Foundations, vol. 53, no. 5, pp. 680-691, 2013.

[8] H. Song, S.-A. Park, M. Choi et al., "Examination of chemical and physical effects on sump screen clogging of containment materials used in Korean plants," Annals of Nuclear Energy, vol. 69, pp. 51-56, 2014.

[9] J. J. Wang, M. Sickinger, V. Ciobota et al., "Revealing the microbial community structure of clogging materials in dewatering wells differing in physico-chemical parameters in an open-cast mining area," Water Research, vol. 63, pp. 222-233, 2014.

[10] J. Poonoosamy, G. Kosakowski, L. R. Van Loon, and U. Mäder, "Dissolution-precipitation processes in tank experiments for testing numerical models for reactive transport calculations: experiments and modelling," Journal of Contaminant Hydrology, vol. 177-178, pp. 1-17, 2015.

[11] A. B. Cunningham, W. G. Characklis, F. Abedeen, and D. Crawford, "Influence of biofilm accumulation on porous media hydrodynamics," Environmental Science and Technology, vol. 25, no. 7, pp. 1305-1311, 1991.

[12] M. Thullner, "Comparison of bioclogging effects in saturated porous media within one- and two-dimensional flow systems," Ecological Engineering, vol. 36, no. 2, pp. 176-196, 2010.

[13] M. Mostafa and P. J. Van Geel, "Validation of a relative permeability model for bioclogging in unsaturated soils," Vadose Zone Journal, vol. 11, no. 1, 2012.

[14] Y. Kuslu and U. Sahin, "A comparison study on the removal of suspended solids from irrigation water with pumice and sandgravel media filters in the laboratory scale," Desalination and Water Treatment, vol. 51, no. 10-12, pp. 2047-2054, 2013.

[15] A. Alem, A. Elkawafi, N.-D. Ahfir, and H. Wang, "Filtration of kaolinite particles in a saturated porous medium: hydrodynamic effects," Hydrogeology Journal, vol. 21, no. 3, pp. 573-586, 2013.
[16] J. Wu, Y. Q. Wu, and J. Lu, "Laboratory study of the clogging process and factors affecting clogging in a tailings dam," Environmental Geology, vol. 54, no. 5, pp. 1067-1074, 2008.

[17] A. H. Fernández-Barrera, D. Castro-Fresno, J. RodriguezHernandez, and Á. Vega-Zamanillo, "Long-term analysis of clogging and oil bio-degradation in a System of Catchment, Pre-treatment and Treatment (SCPT)," Journal of Hazardous Materials, vol. 185, no. 2-3, pp. 1221-1227, 2011.

[18] S.-B. Li, C.-M. Wang, G.-C. Wang, and J.-Q. Ma, "Infiltration clogging test and simulation by PFC3D for loose dam foundation," Journal of Hydraulic Engineering, vol. 43, no. 10, pp. 11631170, 2012.

[19] C. Weidner, S. Henkel, S. Lorke, T. R. Rüde, H. Schüttrumpf, and W. Klauder, "Experimental modelling of chemical clogging processes in dewatering wells," Mine Water and the Environment, vol. 31, no. 4, pp. 242-251, 2012.

[20] S.-Y. Yoo, A. Ueda, and M. Toshifumi, "Experimental studies of injectivity reduction due to carbonate mineralization," Greenhouse Gases: Science and Technology, vol. 3, no. 2, pp. 148-157, 2013.

[21] S.-B. Li, C.-M. Wang, G.-C. Wang, and J.-Q. Ma, "Clogging types distinguishing of coarse-grained soil and determination of optimal range of clogging grain size," Journal of Hydraulic Engineering, vol. 44, no. 10, pp. 1217-1224, 2013.

[22] X. Zengguang, W. Yanqing, W. Jun, and Z. Xiaoqing, "A model of seepage field in the tailings dam considering the chemical clogging process," Advances in Engineering Software, vol. 42, no. 7, pp. 426-434, 2011.

[23] S.-Y. Yoo, Y. Kuroda, Y. Mito et al., "A geochemical clogging model with carbonate precipitation rates under hydrothermal conditions," Applied Geochemistry, vol. 30, pp. 67-74, 2013.

[24] Z. Z. Li, "Modeling precipitate-dominant clogging for landfill leachate with NICA-Donnan theory," Journal of Hazardous Materials, vol. 274, pp. 413-419, 2014.

[25] M. So, D. Naka, R. Goel, M. Terashima, and H. Yasui, "Modelling clogging and biofilm detachment in sponge carrier media," Water Science and Technology, vol. 69, no. 6, pp. 12981303, 2014. 

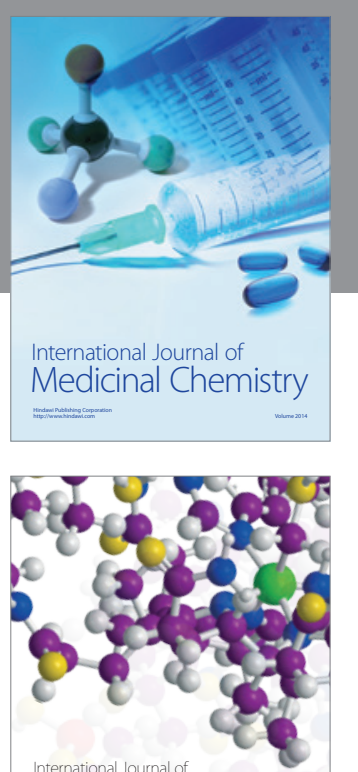

Carbohydrate Chemistry

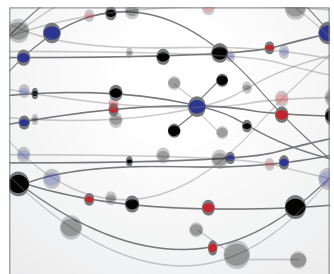

The Scientific World Journal
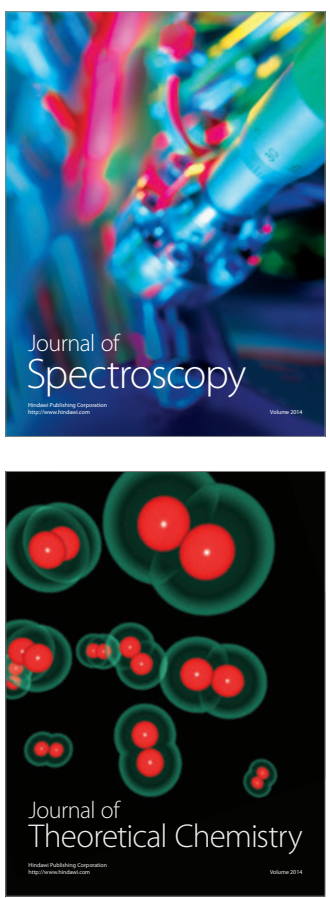
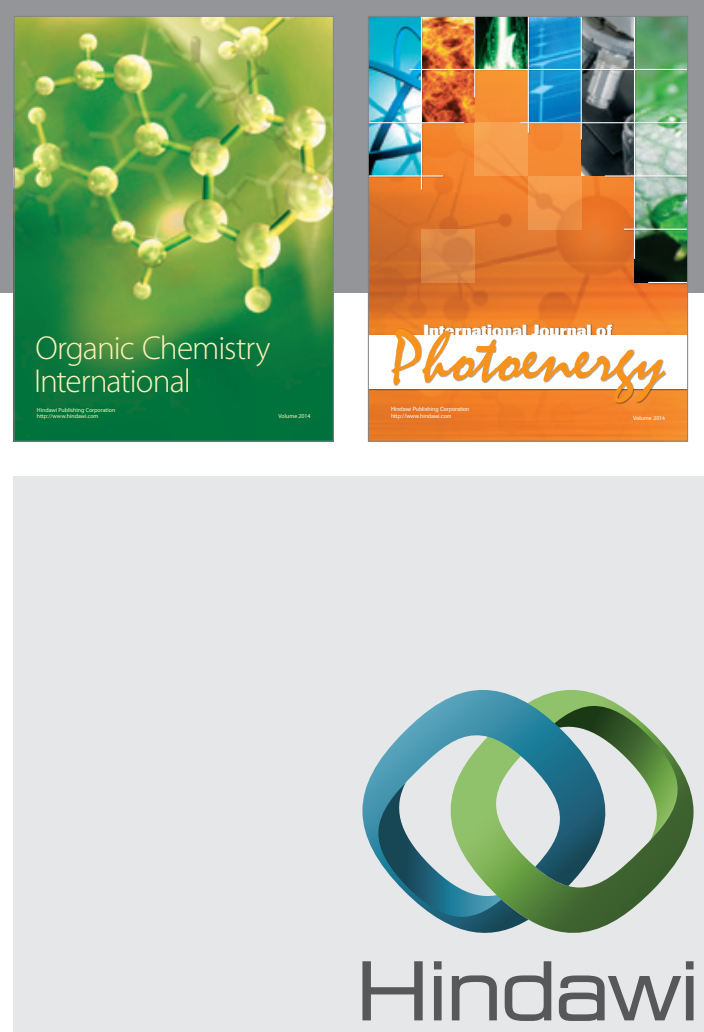

Submit your manuscripts at

http://www.hindawi.com

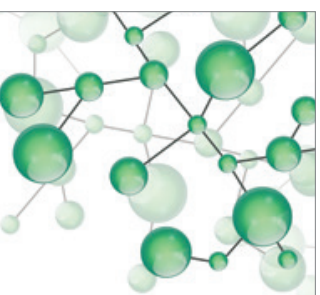

International Journal of

Inorganic Chemistry

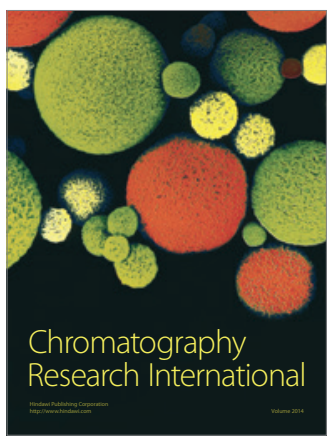

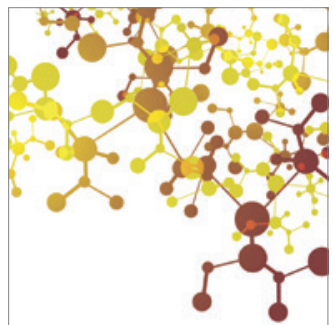

Applied Chemistry
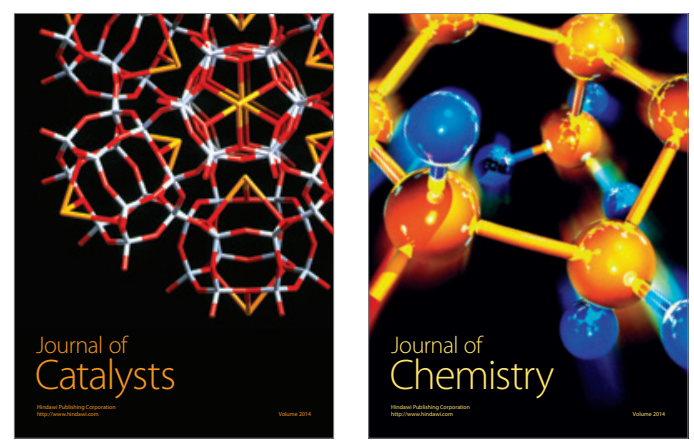
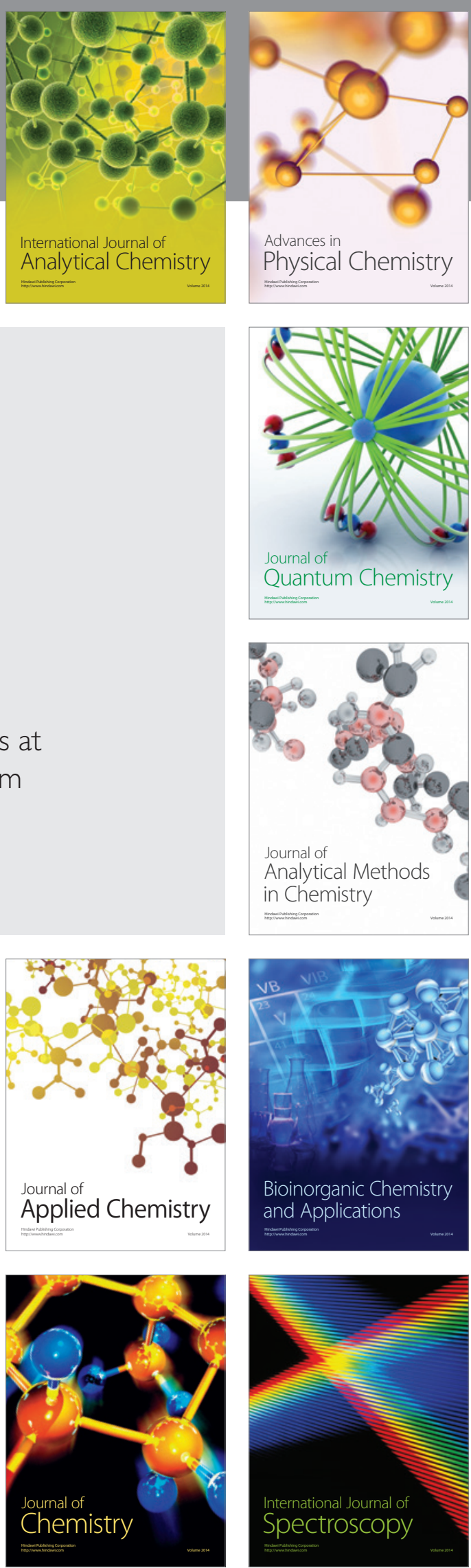